Daria Springer', Szczepan Cofta ${ }^{1}$, Robert Juszkat ${ }^{2}$, Bartosz Żabicki' ${ }^{2}$ Joanna Goździk-Spychalska', Agata Nowicka', Hanna Winiarska', Halina Batura-Gabryel'

'Department of Respiratory Medicine, Allergology and Pulmonary Oncology, University of Medical Sciences, Poznań, Poland

${ }^{2}$ Department of Radiology, Poznań University of Medical Sciences, Poznań, Poland

\title{
The effectiveness of bronchial artery embolisation in patients with haemoptysis
}

\begin{abstract}
Introduction: Bronchial artery embolisation (BAE) is one of the methods used in massive and recurring haemoptysis. The aim of the study is to determine the effectiveness and complications of bronchial artery embolisation in recurring haemoptysis.

Material and methods: The analysis included 47 embolisation procedures performed on 30 patients treated between 2011 and 2017 in the Department of Respiratory Medicine, Allergology and Pulmonary Oncology due to haemoptysis. The patient's age ranged between 18 and 71 years, while mean age at the time of BAE was 33.5 years. Patients with tuberculosis constituted $73.33 \%(n=22)$ of the sample and underwent 31 embolisation procedures in total. The remaining part of the sample $(n=8)$ collectively underwent 16 BAEs. The analysis was conducted by verifying the medical documentation, as well as carrying face-to-face and phone conversations. Results: Immediate control due to the inhibition of bleeding was obtained in $95.75 \%$ of cases. Recurrence within 3 days of BAE was reported in 5 patients $(10.63 \%)$, and 4 re-embolisation procedures were conducted. In 10 patients (33.33\%), recurrence was observed during the first year post-BAE, while it was reported in 17 cases during the whole observation period $(56.66 \%$ of patients). The subjects who underwent re-embolisation demonstrated recurrence-free periods lasting from 2 days to 63 months. In patients with recurrence but no re-embolisation, the shortest and longest haemoptysis-free time was 2 and 35 months, respectively. Eleven patients $(36.66 \%)$ required several embolisation procedures during the whole observation period.

Conclusions: BAE is a highly successful procedure in treating haemoptysis. The risk of complications is low.
\end{abstract}

Key words: embolisation, haemoptysis, cystic fibrosis, lung disease

Adv Respir Med. 2018; 86: 220-226

\section{Introduction}

Haemoptysis stands for coughing up of blood or bloody sputum from the lower parts of the respiratory tract, i.e. from the trachea or bronchi. The loss of $<200 \mathrm{ml}$ during $24 \mathrm{~h}$ does not require surgical intervention. However, coughing up more than $200 \mathrm{ml}$ daily means massive haemoptysis and can be directly life-threatening, which calls for endovascular treatment [1,2].

Bronchial artery embolisation (BAE) is one of the methods used in massive haemoptysis [3-5]. Vascular haemorrhage is a common complication in chronic lung diseases [6]. It can be triggered by: cystic fibrosis [2], lung cancer [7], tuberculosis [4], bronchial and lung inflammations, mycotic infections, as well as congenital defects of pulmonary and cardiac vessels [8]. In the majority of patients, haemoptysis is a complication of destructive changes occurring in bronchial vessels as a result of chronic inflammation in the course of diseases listed above $[1,2]$. This leads to arterial widening and the development of collateral circulation, characterised by fragile, sinuous vessels that can break easily [9].

The aim of the paper is to present the results of a retrospective analysis of the effectiveness of bronchial artery embolisation (taking complications into account) in the Department of Respiratory Medicine, Allergology and Pulmonary Oncology, during the period from 2011 to 2017.

Address for correspondence: Daria Springer, Department of Respiratory Medicine, Allergology and Pulmonary Oncology, Poznań University of Medical Sciences,

Szamarzewskiego 82/84,60-569 Poznań, Poland, e-mail: daria.springer.pl@gmail.com

DOI: $10.5603 /$ ARM.2018.0035

Received: 22.07 .2018

Copyright (C) 2018 PTChP

ISSN 2451-4934 


\section{Material and methods}

30 patients were treated in the Department by means of endovascular embolisation between 2011 and 2017. BAE was conducted due to massive and/or recurring haemoptysis. Most of the patients were previously treated by means of other methods, including pharmacological treatment, which failed to stop haemoptysis.

In the paper, we report on the analysis of embolisation conducted on different patients, irrespective of haemoptysis aetiology. Patients with cystic fibrosis constituted $73.33 \%(n=22)$ of the sample, and collectively underwent 31 embolisation procedures. The remaining part of the sample ( $\mathrm{n}=8,26.7 \%$ ) was composed of patients with: pulmonary aspergillosis $(n=3)$, silicosis $(n=1)$, right lung hypoplasia $(\mathrm{n}=1)$, lung fibrosis subsequent to mediastinal seminoma radiotherapy $(\mathrm{n}=1)$, pulmonary mycobacteriosis $(\mathrm{n}=1)$ and bronchiectasis $(n=1)$. Sixteen embolisation procedures were performed.

The patients underwent embolisation at the Department of Respiratory Medicine, Allergology and Pulmonary Oncology, following diligent clinical assessment. The planned angiographic procedure was preceded by CT angiography scan (CT-angio scan), in order to assess pulmonary parenchyma, especially the number, anatomy and anatomical variety of bronchial arteries. Due to its high sensitivity and specificity, CT angiography is a method of choice in diagnosis of heamoptisis. It's helpful in diagnosis of bleeding localisation and its cause, and has a significant impact on deciding further therapeutic options. Efficacy in determining bleeding site is estimated at $63-100 \%$. Given CT angiography short duration, it may be only diagnostic possibility in urgent emergency, which massive haemoptysis often is [10-12].

Individuals with cystic-fibrosis-induced haemoptysis had all bronchial arteries that could be subject to embolised catheterisation. In the rest of patients, embolisation was conducted for only those arteries which led to the area suspected to be the source of haemorrhage, based on bronchoscopy and CT-angio scan.

Common femoral artery access was used as the route in BAE procedures. Pathologically changed vessels were identified by means of digital subtraction angiography (DSA), conducting a preliminary descending aorta aortogram (Fig. 1). Subsequently, bronchial branches were selectively catheterised by means of $4 \mathrm{~F}$ or $5 \mathrm{~F}$ catheters. Embolisation was conducted using polyvinyl alcohol (PVA) embolisation particles

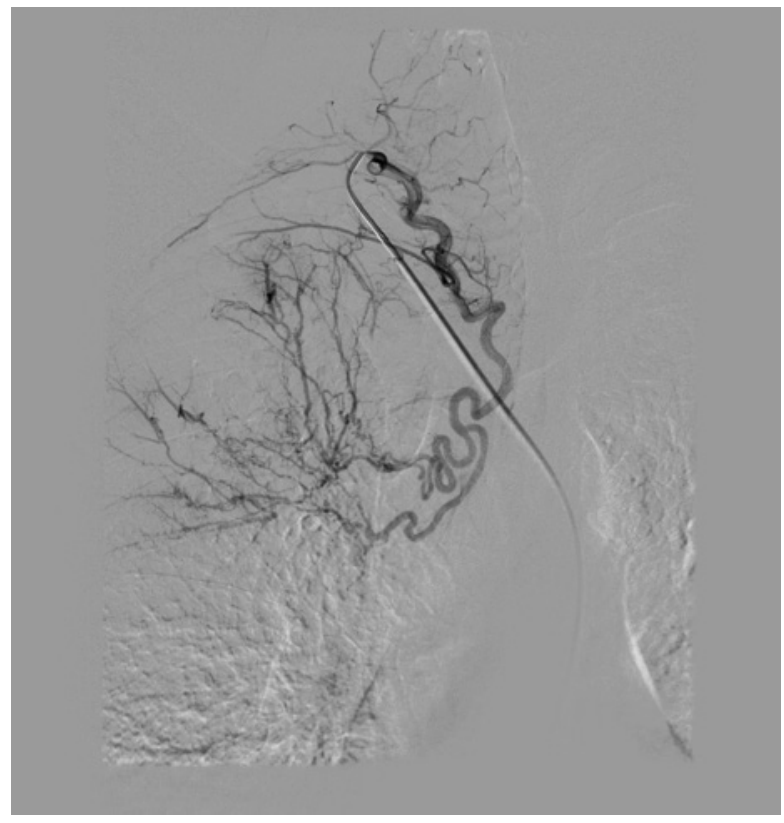

Figure 1. Pathologically changed vessels identified by means of digital subtraction angiography (DSA), conducting a preliminary descending aorta aortogram

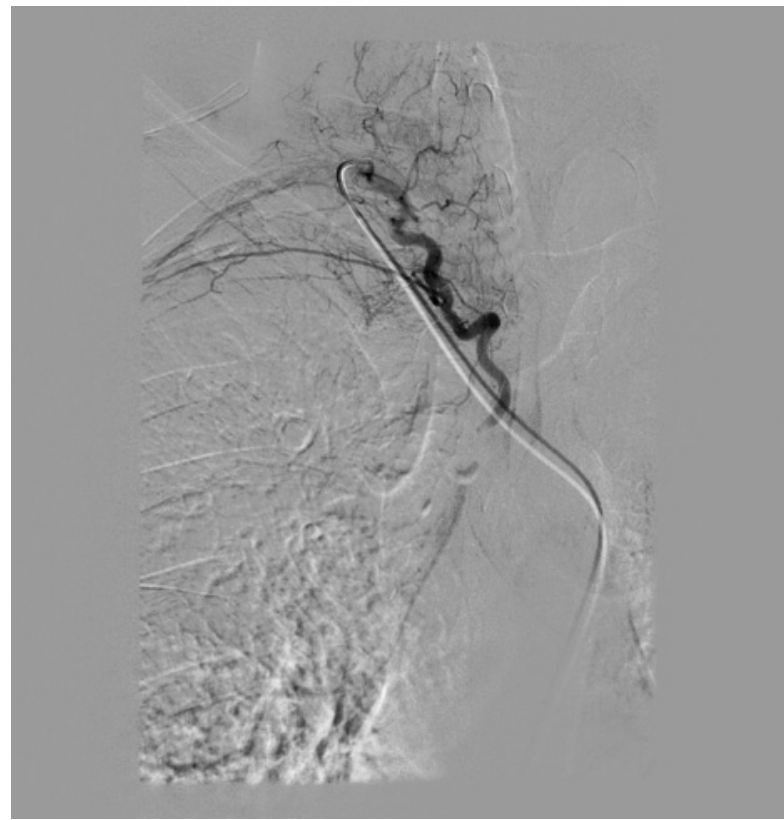

Figure 2. Embolisation conducted using polyvinyl alcohol (PVA) embolisation particles (Cook) whose size was 300 to $2000 \mu \mathrm{m}$

(Cook) whose size was 300 to $2000 \mu \mathrm{m}$ (Fig. 2). In addition, a microcatheter was introduced in the case the regular catheter was unstable, or when embolisation liquids (Squid) or detachable spirals were used.

The number of patients who underwent embolisation by means of PVA was equal to 28 
(mean age: 33 yo, range: 18-71 yo). In addition, there was 1 patient ( 26 yo) in whom embolisation spirals were used. Finally, also 1 patient (36 yo) was subjected to different BAE methods: first, a procedure with detachable spirals and Squid , which was followed 6 days later by PVA embolisation.

\section{Results}

Thirty patients with recurring and/or massive haemoptysis required bronchial artery embolisation. The average time of observation was 22.8 months, and ranged from 5 days to 84 months. Contact with 3 patients was lost immediately after hospitalisation during which embolisation was conducted. Another 5 patients discontinued the contact during the observation period (mean time from BAE to contact loss: 23 months, ranging from 5 to 52 months).

Immediate haemorrhage inhibition during the first 24 hours post-embolisation was achieved in 95.75\% of patients (haemoptysis recurred within several hours in two patients). Haemoptysis recurrence within 3 days post-BAE was observed in 5 patients $(10.63 \%)$. Four re-embolisation procedures were conducted during the same hospital stay. Haemoptysis recurred within the first year post-embolisation in 10 patients (33.33\%), and in 17 patients (56.66\%) during the total period of observation.

Eleven out of 17 patients (64.71\%) with recurring haemoptysis required another endovascular bronchial artery embolisation procedure. Eight of those patients had two embolisation procedures, 1 patient - three, 1 patient - four, and another 1 patient - five embolisation procedures performed. In total, 28 BAEs (17 re-embolisation procedures) were conducted in those patients. The remaining 6 patients experienced minor haemoptysis which stopped following conservative treatment.
Three patients underwent lung transplant surgery during the observation period. The average time between the last BAE and lung transplant was 15 months, ranging from 3 to 28 months.

Pneumonectomy of the right lung was performed in one patient 2 months following the last BAE.

Six patients died during the observation, including 5 patients with cystic fibrosis and 1 patient with pulmonary mycetoma. The average time between the last BAE and patient's death was 16.5 months, ranging from 3 to 38 months.

The number of embolisation procedures goes as follows for different methods: 45 (95.74\%) embolisation procedures with PVA particles, $1(2.13 \%)$ spiral embolisation and $1(2.13 \%)$ spiral + Squid embolisation. The vast majority of BAEs (45 out of 47) was conducted by means of PVA particles, and therefore comparing this method to the other ones ( 2 out of 47 BAEs) would be inconclusive.

In order to determine the shortest and the longest haemoptysis-free period, patients were divided into three groups. The first group was composed of individuals in whom re-embolisation was performed due to massive haemoptysis (Table 1); the second group included patients with minor haemoptysis (blood-tinged sputum, coughing up single blood lines) who did not require any surgical intervention; in turn, the third group was composed of patients with no recurrence.

11 individuals were present in the first group. The shortest bleeding-free interval was several hours while the longest one lasted 63 months. The shortest recurrence-free period between the first and second BAE (11 procedures, average time: 13 months) was equal to 2 days, while the longest one was 63 months. The shortest recurrence-free period between the second and third BAE ( 3 procedures, average

Table 1. Time between consecutive embolizations in patients with recurrent hemoptysis

\begin{tabular}{|c|c|c|c|c|c|c|c|c|c|c|c|}
\hline BAE/PT & Pt 2 & Pt 3 & Pt 6 & Pt 7 & Pt 8 & Pt 12 & Pt 14 & Pt 16 & Pt 17 & Pt 25 & Pt 28 \\
\hline $1-2$ & 3 months & $\begin{array}{c}63 \\
\text { months }\end{array}$ & $\begin{array}{c}22 \\
\text { months }\end{array}$ & 2 days & $\begin{array}{c}13 \\
\text { months }\end{array}$ & $\begin{array}{c}10 \\
\text { months }\end{array}$ & $\begin{array}{c}14 \\
\text { months }\end{array}$ & $\begin{array}{c}10 \\
\text { months }\end{array}$ & 5 days & 4 months & 11 days \\
\hline $2-3$ & 8 months & & $\begin{array}{c}17 \\
\text { months }\end{array}$ & & & & & & & 11 days & \\
\hline $3-4$ & $\begin{array}{c}16 \\
\text { months }\end{array}$ & & $\begin{array}{c}13 \\
\text { months }\end{array}$ & & & & & & & & \\
\hline $4-5$ & 5 days & & & & & & & & & & \\
\hline
\end{tabular}

BAE: bronchial artery embolization; Pt: patient 
time: 8 months) lasted 11 days, and the longest: 17 months. The shortest recurrence-free period between the third and fourth BAE (2 procedures, average time: 15 months) was 13 months, while the longest one lasted 16 months. Finally, in one patient, a fifth BAE was performed five days after the fourth one.

Six patients were included in the second group. The shortest recurrence-free period was 2 months, and the longest one: 35 months.

Patients in whom recurrence did not occur were under observation from 5 to 38 months.

In general, haemoptysis-free time averaged for all 30 patients was equal to 15.8 months.

Minor post-BAE complications reported by the patients included haematoma at the site of microcatheter insertion $(n=1)$, fever $(n=1)$ and vomiting $(\mathrm{n}=2)$.

The patients' data, information on embolisation, haemoptysis-free period, other medical incidents and the death of observed patients are presented in Table 2.

\section{Discussion}

While all the procedures were effective, recurrence was observed in two patients as soon as several hours post-BAE. Bleeding control during the first 24 hours post-BAE reached the level of $95.74 \%$. In the course of the long-term observation, haemoptysis recurrence was reported in $33.33 \%$ of patients. In general, recurrence was observed in $56.66 \%$ of the subjects. These results are in accordance with the outcomes obtained in other centres [13-17].

Tape et al. [13] conducted an observation on 15 patients with cystic fibrosis in whom 33 BAEs were performed. The mean time of observation was 72 months, ranging from 3 to 168 months. The procedures resulted in $100 \%$ of haemoptysis inhibition, while recurrence was reported in $60 \%$ of patients during the whole time of observation.

In turn, Shin et al. [14] described a group of 398 patients with tuberculosis who underwent BAE. The reported effectiveness of BAE during the first 24 hours was $96.4 \%$, while recurrence was observed in $48.6 \%$ of patients post-BAE.

Rashad et al. [15] embarked on a study on 47 patients with massive haemoptysis, who were observed for 6 months post-embolisation.
Re-embolisation was conducted in 2 patients due to bleeding recurrence. The following causes of haemoptysis were reported: active tuberculosis, post-tuberculosis changes in pulmonary parenchyma and bronchiectasis.

Endovascular embolisation is also effective in aspergillosis. Corr et al. [16] conducted an observation on 12 patients with aspergillosis and reported 1 haemoptysis recurrence within 4 weeks post-BAE.

The effectiveness of endovascular embolisation is high. That notwithstanding, the risk of death, lung transplant or pneumonectomy is increased in the group of patients who once suffered from haemoptysis, even if they were successfully treated with embolization [17].

Vidal et al. [17] compared 30 patients with tuberculosis, in whom massive haemoptysis was treated with embolisation (42 procedures were conducted) to a control group including 27 healthy patients, matched for sex, age and $\mathrm{FEV}_{1}$ value in spirometry. Among patients undergoing BAE, haemoptysis was inhibited during the first 24 hours in $96.6 \%(n=29)$ of cases. A 5-year-long observation showed that 9 patients underwent transplantation, in comparison to 1 patient in the control group. Patients undergoing embolisation due to arterial bleeding are under increased risk of lung function deterioration, the need to have a lung transplant, or death.

3 out of 30 patients observed in our Department required lung transplant (patients with tuberculosis), while 1 was in need for right lung pneumonectomy (patient with aspergillosis).

\section{Conclusions}

Bronchial artery embolisation was highly successful shortly after the procedure (95.74\% during the first 24 hours). Recurrence occurred within 1 year in $33.33 \%$ of patients, while a single re-embolisation was successful in half of the sample in the long perspective.

BAE is burdened with a low level of complications. It can be repeated if needed, including once-treated vessels where recanalisation occurred [18].

\section{Conflict of interest}

The authors declare no conflict of interest. 


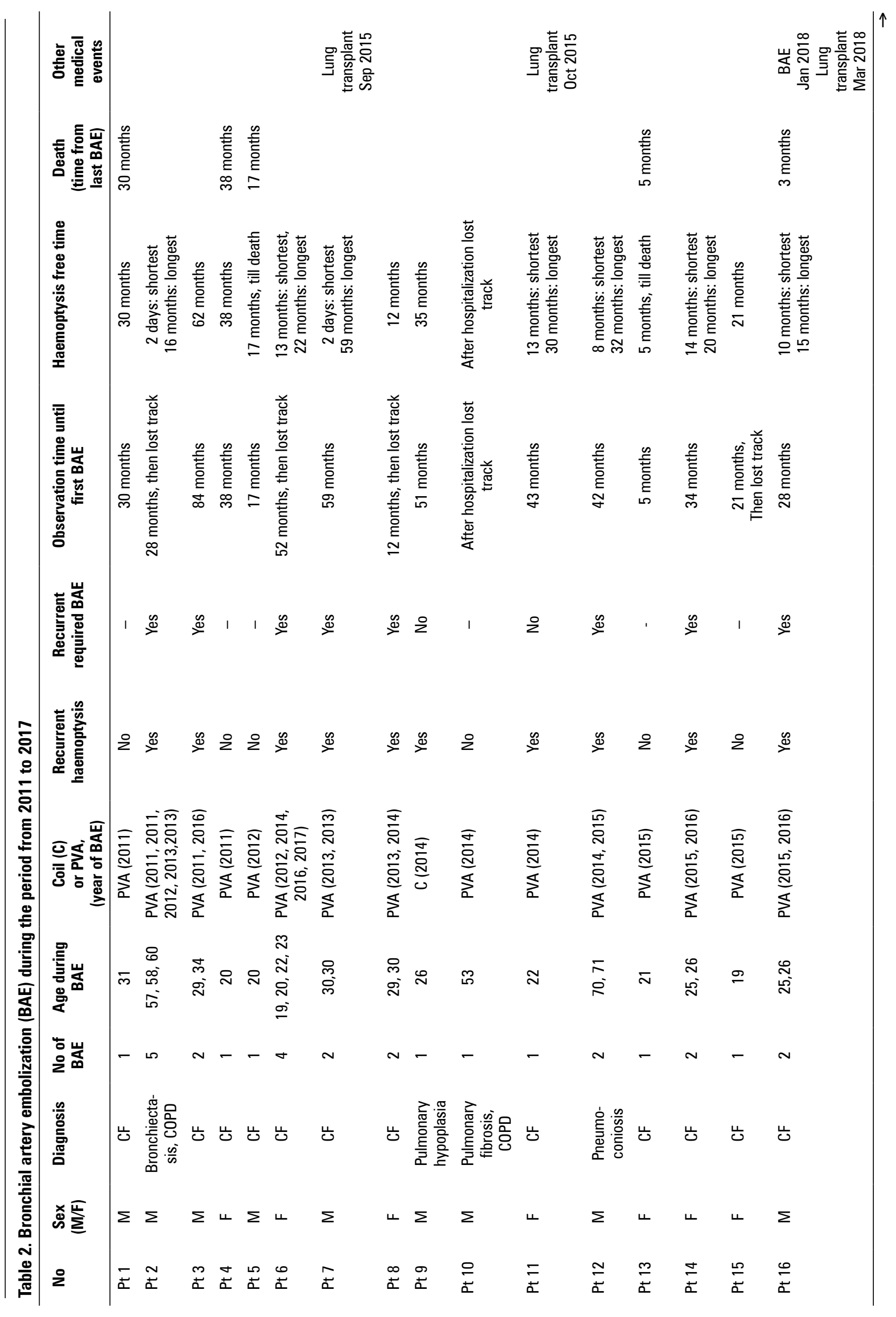




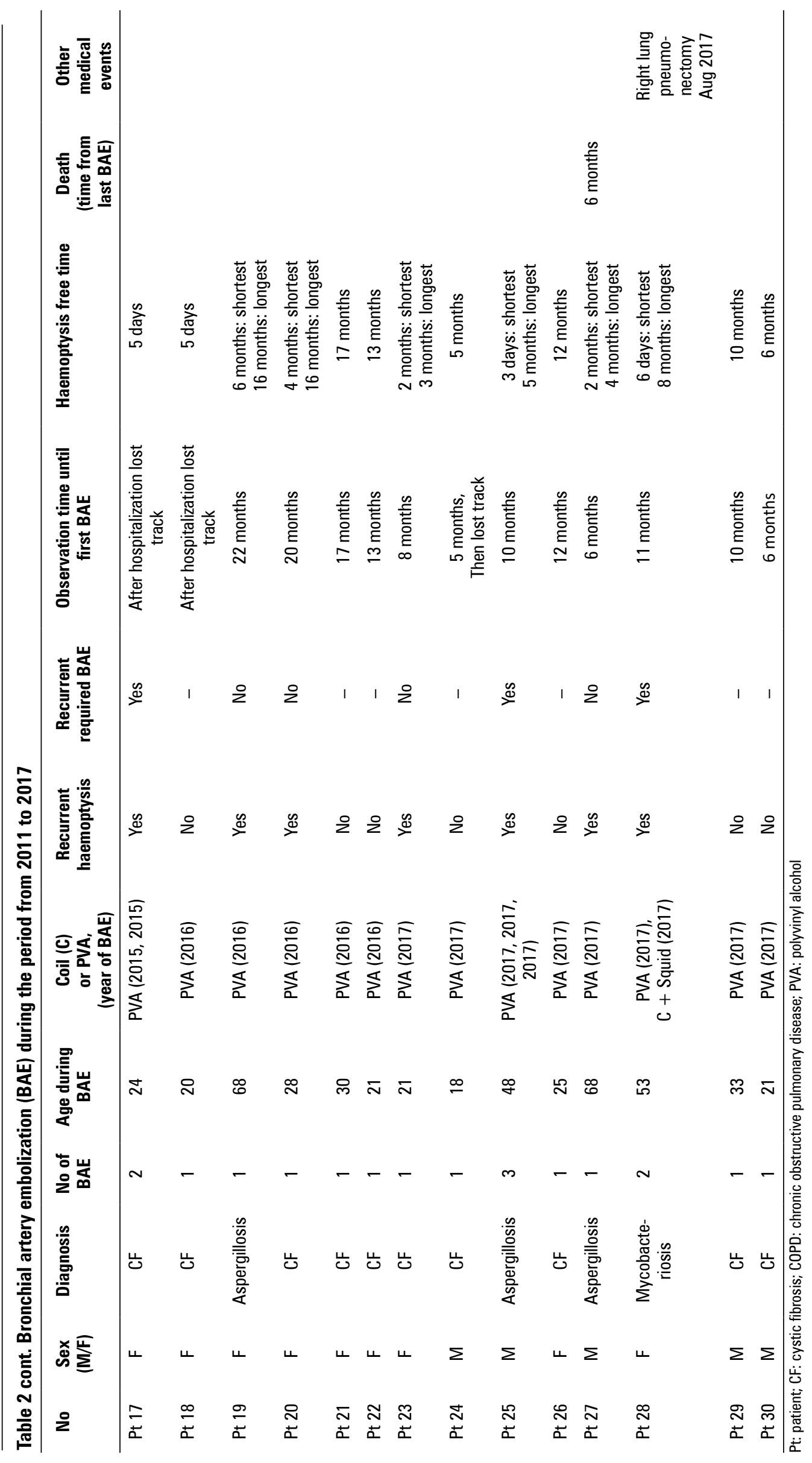




\section{References:}

1. Gajewski P, Niżankowska-Mogilnicka E. Interna Szczeklika. Medycyna Praktyczna, Kraków 2017: 609-610.

2. Sands D. Mukowiscydoza. Choroba wieloukładowa. Termedia Wydawnictwa Medyczne 2018.

3. Fruchter O, Schneer S, Rusanov V, et al. Bronchial artery embolization for massive hemoptysis: long-term follow-up. Asian Cardiovasc Thorac Ann. 2015; 23(1): 55-60, doi: 10.1177/0218492314544310, indexed in Pubmed: 25053662.

4. Anuradha C, Shyamkumar NK, Vinu M, et al. Outcomes of bronchial artery embolization for life-threatening hemoptysis due to tuberculosis and post-tuberculosis sequelae. Diagn Interv Radiol. 2012; 18(1): 96-101, doi: 10.4261/1305-3825. DIR.3876-11.2, indexed in Pubmed: 21678246.

5. Fernando HC, Stein M, Benfield JR, et al. Role of bronchial artery embolization in the management of hemoptysis. Arch Surg. 1998; 133(8): 862-866, indexed in Pubmed: 9711960.

6. Yoon W, Kim JK, Kim YH, et al. Bronchial and nonbronchial systemic artery embolization for life-threatening hemoptysis: a comprehensive review. Radiographics. 2002; 22(6) 1395-1409, doi: 10.1148/rg.226015180, indexed in Pubmed: 12432111.

7. Bleakley S, Phipps K, Petrovsky B, et al. CKD Prognosis Consortium, Prophylactic Cranial Irradiation (PCI) Collaborative Group, Emerging Risk Factors Collaboration. Escalated dose for non-small-cell lung cancer with accelerated hypofractionated three-dimensional conformal radiation therapy. Radiother Oncol. 2004; 71(2): 163-166, doi: 10.1016/j.radonc.2003.09.006, indexed in Pubmed: 15110449.

8. Jassem E, Jassem J. Pulmonary bleedings. Adv Palliat Med. 2003; 2(1): 23-30.

9. Brinson GM, Noone PG, Mauro MA, et al. Bronchial artery embolization for the treatment of hemoptysis in patients with cystic fibrosis. Am J Respir Crit Care Med. 1998; 157(6 Pt 1): 1951-1958, doi: 10.1164/ajrccm.157.6.9708067, indexed in Pubmed: 9620932.
10. Chalumeau-Lemoine L, Khalil A, Prigent H, et al. Impact of multidetector CT-angiography on the emergency management of severe hemoptysis. Eur J Radiol. 2013; 82(11): e742e747, doi: 10.1016/j.ejrad.2013.07.009, indexed in Pubmed: 23932395.

11. Khalil A, Fedida B, Parrot A, et al. Severe hemoptysis: From diagnosis to embolization. Diagn Interv Imaging. 2015; 96(7-8): 775-788, doi: 10.1016/j.diii.2015.06.007, indexed in Pubmed: 26141487.

12. Noë GD, Jaffé SM, Molan MP. CT and CT angiography in massive haemoptysis with emphasis on pre-embolization assessment. Clin Radiol. 2011; 66(9): 869-875, doi: 10.1016/j. crad.2011.03.001, indexed in Pubmed: 21658690.

13. Tepe S. Long term outcomes of bronchial artery embolization for hemoptysis in patients with cystic fibrosis. Gulhane Medical Journal. 2013; 55(1): 27, doi: 10.5455/gulhane.17220.

14. Shin BS, Jeon GS, Lee SA, et al. Bronchial artery embolisation for the management of haemoptysis in patients with pulmonary tuberculosis. Int J Tuberc Lung Dis. 2011; 15(8): 1093-1098, doi: 10.5588/ijtld.10.0659, indexed in Pubmed 21740674.

15. Rashad A, Amin M, El-Azim A, et al. Percutaneous transcatheter vascular embolization for life threatening hemoptysis. Egyptian Journal of Chest Diseases and Tuberculosis. 2013; 62(4): 755-759, doi: 10.1016/j.ejcdt.2013.09.009.

16. Corr P. Management of severe hemoptysis from pulmonary aspergilloma using endovascular embolization. Cardiovasc Intervent Radiol. 2006; 29(5): 807-810, doi: 10.1007/s00270005-0329-0, indexed in Pubmed: 16810459.

17. Vidal V, Therasse E, Berthiaume Y, et al. Bronchial artery embolization in adults with cystic fibrosis: impact on the clinical course and survival. J Vasc Interv Radiol. 2006; 17(6): 953-958, doi: 10.1097/01.RVI.0000222822.82659.50, indexed in Pubmed: 16778227.

18. Juszkat R, Cofta S, Stanisławska K, et al. Embolizacja tętnicy oskrzelowej w leczeniu nawracającego krwioplucia u pacjentka z mukowiscydozą. Przegl Lek. 2012; 69(7): 347-349. 